\title{
Wind tunnel study of gas dispersion in the presence of a rectangular building
}

\author{
P. Michalek \& D. Zacho \\ Department of Aerodynamics, Aerospace Research and Test \\ Establishment (VZLU), Prague, Czech Republic
}

\begin{abstract}
Dispersion of non-buoyant and dense gas emitted out of a ground level source was studied in a boundary layer wind tunnel. Concentration of gas was measured on a simple rectangular building model using suction taps and a flame ionisation detector. Influence of windward or leeward orientation of the facade with suction taps as well as influence of velocity above the boundary layer was studied. Results have proved significant differences of gas concentration on the windward and leeward side, also differences in concentration according to height above the tunnel floor were observed.

Keywords: gas dispersion, boundary layer wind tunnel, rectangular building model, flame ionisation detector.
\end{abstract}

\section{Introduction}

Harmful gas releases in urban areas belong to serious environmental problems. Since the gas tanks in industrial plants are often located inside or near populated urban areas, many people may be in health risk or even life risk during gas exposure. These releases may occur due to accidents or terrorist attacks and are affected by meteorological conditions, i.e. wind speed and wind direction, air pressure, temperature and humidity. The dispersion of released gases is also influenced by buildings, especially in case of heavy and non-buoyant gases dispersion. These gases may endanger human life and health the most, because these gases disperse near the ground.

In order to avoid casualties in a most possible manner, life rescue services have to know the extent of the accident, respectively to have a tool that enables to estimate the extent of the accident. For this purpose, a computational tool for 
gas dispersion estimation is being developed in VZLU. This tool will use precalculated data of dispersion near chosen industrial plants in the Czech Republic to estimate the progress of dispersion under actual meteorological conditions. This software will predict the size of contaminated area and thus enable fast and effective action of rescue services.

\section{Experimental facility in VZLU}

\subsection{Boundary layer wind tunnel}

A boundary layer wind tunnel (BLWT) in VZLU has been used for so-called physical modelling, which means experimental verification and evaluation of computational data. The scheme of BLWT in VZLU is presented in Fig. 1. Wind direction is from left to right.

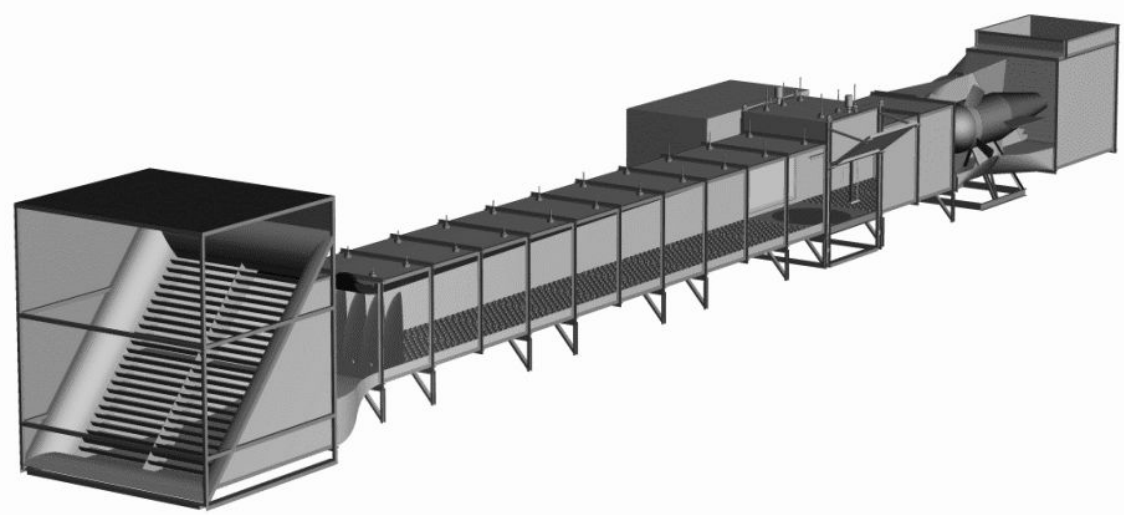

Figure 1: $\quad$ BLWT in VZLU Prague.

The BLWT is equipped with $55 \mathrm{~kW}$ DC engine and this engine generates maximal wind speed $25 \mathrm{~m} / \mathrm{s}$ above the boundary layer. Working section of the tunnel, where boundary layer develops, is $13,3 \mathrm{~m}$ long with vortex generator at the beginning. The test section where experiments take place is $2 \mathrm{~m}$ long, $1,8 \mathrm{~m}$ wide and 1,5 $\mathrm{m}$ high. Test section contains a turntable $1,7 \mathrm{~m}$ in diameter for the purpose of wind direction change. Both sections have an adjustable ceiling in order to adjust and maintain constant longitudinal pressure gradient. Pressure in all sections is monitored and displayed in computer. Test section is also supplied with traversing device, which enables to move probes in all three directions $\mathrm{x}, \mathrm{y}$ and $\mathrm{z}$. This section is accessible through windows located on both sides of the tunnel.

Instrumentation of the tunnel includes hot-wire anemometer with different probes, pressure scanner, hydrocarbon tracing and detection system with flame ionisation detector and particle image velocimetry (PIV) devices, i.e. laser with optics and high-speed camera. Velocity above the boundary layer is monitored via Pitot-static probe and hot-wire transducer probe. 
In recent years many dispersion studies were made in VZLU, such as simulation of stack plumes by Jirsak and Ulman [1], gas leakages from railway station and heavy gas dispersion by Ulman [2] and Ulman et al. [3], pressure and concentration experiments on building model for ventilation optimization by Jirsak et al. [4] and infiltration into building model by Michalek and Zacho [5]. Most recent work concerning gas dispersion by Michalek and Zacho [6] was presented at the Air Pollution XX conference in the year 2012.

Experimental research on the field of gas dispersion was widely performed in the world. Meroney et al. [7] have studied flow and dispersion about some building shapes, Chavez et al. [8] have studied pollutant dispersion from stack placed on top of building, Robins et al. [9] made a wind tunnel study of dense gas dispersion in neutral boundary layer, Janour et al. [10] performed a wind tunnel study of dispersion over an industrial site, Roberts and Fryer-Taylor [11] have investigated roughness effects on gas dispersion, and many others. General guidelines for dispersion experiments were given by Snyder [12] and guidelines for wind tunnel testing by ASCE publication No. 67 [13].

\subsection{Boundary layer modeling}

In order to maintain similarity to the Earth boundary layer (in neutral temperature condition), some similarity condition have to be adhered. First, the incoming boundary layer must have fully developed turbulent flow, which is indicated on the velocity profile. The mean velocity profile measured with hotwire probe is shown in Fig. 2. This profile was measured at the beginning of the test section, ergo it indicates the incoming boundary layer. The logarithmic law is defined for indifferent atmospheric layering as

$$
U(z)=\frac{u^{*}}{k} \cdot \ln \left[\frac{z-d}{z_{o}}\right]
$$

where $\mathrm{u}^{*}$ is frictional velocity (dynamic velocity), $\mathrm{k}=0.4$ is von Karman's constant, $\mathrm{z}_{\mathrm{o}}$ is aerodynamic roughness, $\mathrm{d}$ is zero plane displacement, $\mathrm{U}$ is mean velocity a $\mathrm{z}$ is vertical coordinate. Second condition involves overcritical Reynolds roughness number $\mathrm{Re}^{*}=\mathrm{z}_{0} \cdot \mathrm{u}^{*} / \mathrm{v}$, where $\mathrm{v}$ is cinematic viscosity of air $\left[\mathrm{m}^{2} / \mathrm{s}\right]$. For the purpose of gas dispersion modeling this condition can be relaxed up to $\mathrm{Re}^{*} \geq 1,0$. Third necessary condition for modeling turbulent boundary layer is that the power spectrum of boundary layer contains the so-called "inertial subarea”, which means that part of the power spectral density agrees with the “-5/3-power slope curve”. Mentioned parameters of the boundary layer are in table 1. Simulated boundary layer corresponds to the IIIrd terrain category according to Eurocode 1 (EC1) [14]. 
Table 1: $\quad$ Parameters of the boundary layer.

\begin{tabular}{|l|l|l|l|l|l|}
\hline $\begin{array}{l}\text { Terrain } \\
\text { category }\end{array}$ & $\begin{array}{l}\text { Simulation } \\
\text { means }\end{array}$ & $\mathrm{Z}_{0}[\mathrm{~mm}]$ & $\mathrm{u}^{*}[\mathrm{~m} / \mathrm{s}]$ & $\mathrm{d}[\mathrm{mm}]$ & $\mathrm{Re}^{*}[-]$ \\
\hline III. (EC1) & $\begin{array}{l}\text { Plastic sheet } \\
\text { with 8mm } \\
\text { cones+ } \\
140 \mathrm{~mm} \text { barrier }\end{array}$ & 0.827 & 0.183 & 5.0 & 9.80 \\
\hline
\end{tabular}

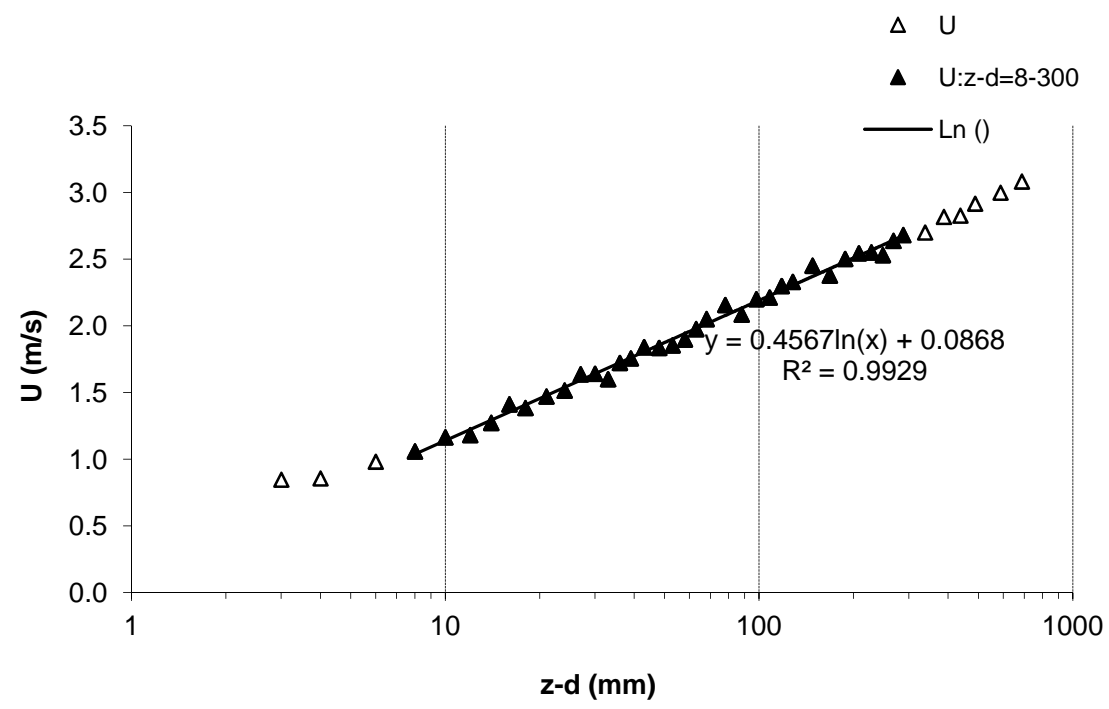

Figure 2: $\quad$ Vertical velocity profile.

\subsection{Gas dispersion modeling}

The equipment for gas dispersion modeling includes pressure vessels with gases, electronic flow controllers (Alicat Scientific), tubing and emission source. Measuring devices include model with sampling taps, silica capillary tubing, peristaltic pump and four flame ionisation detectors (FID) with electrometers EL-980, which are connected to a computer with A/D card from National Instruments company. The measuring principle of flame ionisation detector is based on measuring electric current changes in hydrogen flame. The changes are caused by incoming sample containing hydrocarbon tracing gas - ethane. The electric signal can be recalculated into concentration according to calibration of the FIDs, which is made with mixture of gases of known concentration.

The emission source was designed in order to simulate ground level continuous emissions of gases from some smaller industrial chemical plants or gas tanks. This source consists of small chamber sized $30 \times 30 \times 10 \mathrm{~mm}$ whose one side of rectangular size 25x25 mm was covered with porous fabric used in air-condition filters. This topside of the source was placed in the wind tunnel 
floor level in the centre of the turntable. This fabric in the source top allows slowing down gas emission velocity, therefore the emission exit velocity is much lower than ambient flow velocity.

For this research, a simple rectangular building model with dimensions $170 \mathrm{x}$ 170 x $60 \mathrm{~mm}$ (width $\mathrm{x}$ height $\mathrm{x}$ depth) was made of hard aluminium plates. The model was then fitted with eight sampling taps of internal diameter $1,5 \mathrm{~mm}$. The taps are located at the centreline of the model, where six of them are on the façade and two are located on the roof. For accurate location (see Fig. 3). Small numbers along the centreline denote tap distances in $\mathrm{mm}$, where bigger numbers are tap positions. The taps are connected via silica capillary tubing going through the internal volume of the model and then behind the model on the wind tunnel floor to the FIDs. Measuring on both windward and leeward side of the model is made possible by simply rotating the model in 180-degree angle so that the façade with taps is located on windward or leeward side.

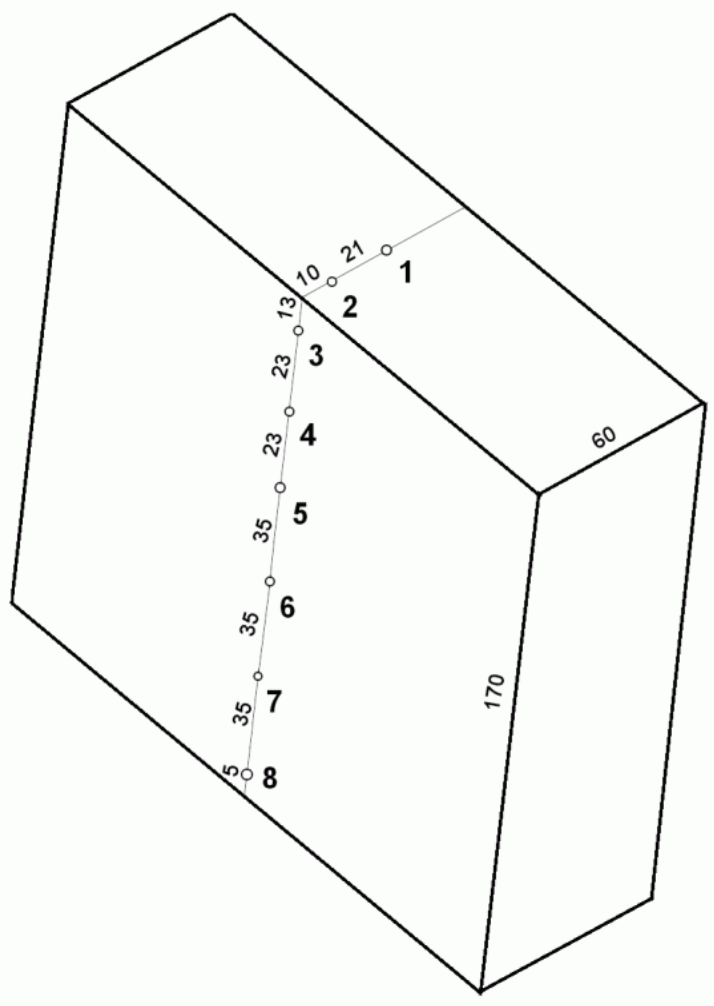

Figure 3: $\quad$ Model building with taps.

The gases, i.e. air and sulfur hexafluoride $\left(\mathrm{SF}_{6}\right)$ and ethane were dosaged using electronic flow controllers Alicat Scientific. $\mathrm{SF}_{6}$ is non-toxic and nonflammable gas with density 5,1-times bigger than air at normal conditions $\left(20^{\circ} \mathrm{C}\right.$, 
1 bar). $\mathrm{SF}_{6}$ is used mainly as insulation gas in high voltage devices. The gases were released into tube leading to the point source in the wind tunnel floor. Volume flow of air or $\mathrm{SF}_{6}$ was set to 1,3 or $3,0 \mathrm{l} / \mathrm{min}$, ethane flow was set to 0 $2,5 \mathrm{l} / \mathrm{min}$ in steps of $0,25 \mathrm{l} / \mathrm{min}$ in order to study the influence of increasing ethane concentration on the dispersion process. FID calibration was made with calibration gas of known concentration 100 ppm (parts per million) ethane in air. The frequency response of this measuring chain is max. $10 \mathrm{~Hz}$, the sampling frequency was set to $100 \mathrm{~Hz}$ and measuring time for one point was $60 \mathrm{~s}$. Two basic gas mixtures were used, namely air with ethane for modeling of neutral buoyant emission and $\mathrm{SF}_{6}$ with ethane for dense emission modeling. In order to create different emission momentum, different volume flow of air or $\mathrm{SF}_{6}$ was used. Here 1,3 l/min volume flux stands for lower momentum and 3,0 l/min stands for higher momentum.

Figure 4 presents building model installed in the wind tunnel at distance $1 \mathrm{H}$ beyond the source (white square) in the wind tunnel floor.

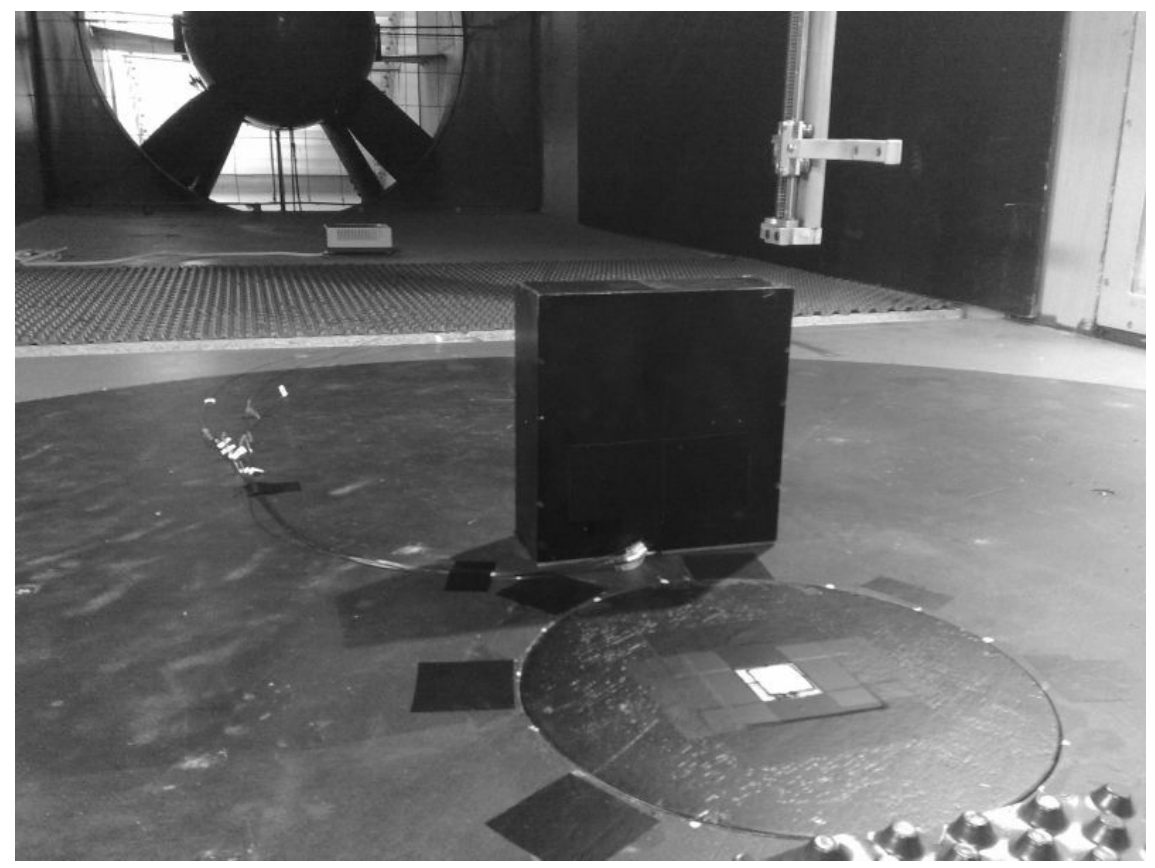

Figure 4: Model building with taps installed in the wind tunnel beyond the source.

\section{Results and discussion}

Measuring program is based on National Instruments LabView 11.0 environment and allows calibration, on-line viewing and recording the voltage signal from FIDs, which is received via PCI A/D card also by National Instruments. Voltage 
signal for natural background concentration was measured and subtracted prior to measuring with ethane.

Measured tracer gas concentrations in ppm were converted into dimensionless concentration $\mathrm{C} / \mathrm{C}_{0}$, where $\mathrm{C}_{0}$ was initial concentration in ppm of tracer gas entering the source via tube. Data analysis and graphic workspace software Origin 8 was used for displaying measured results and creating graphs. The value of $\mathrm{z} / \mathrm{H}=0$ presents background concentration in the wind tunnel measured on tunnel wall. Negative concentration values should be considered as zero, these values occur probably due to calculation of the mean values from the FID voltage signal. The taps are plotted in graphs with their increasing $\mathrm{z} / \mathrm{H}$ value, ergo the sequence on horizontal axis is from left to right: background, taps no. 8, $7,6,5,4,3,2,1$.

Figures 5 to 10 show measured concentrations for windward and leeward façade orientation, distance from the source $0,5 \mathrm{H}$ or $1 \mathrm{H}$ and air or SF6 emission. Results showed that windward façade concentration in the façade centre was much lower than the leeward one, probably because the fact of very high turbulence in the wake of the building, which allowed mixing of the emission gases and remaining in the wake area for longer time. The concentration on leeward side was decreasing slowly in the direction upward from ground level. On windward side, the concentration decreased to zero at central part of the façade and then increased again at the roof $(\mathrm{z} / \mathrm{H} \geq 1)$.

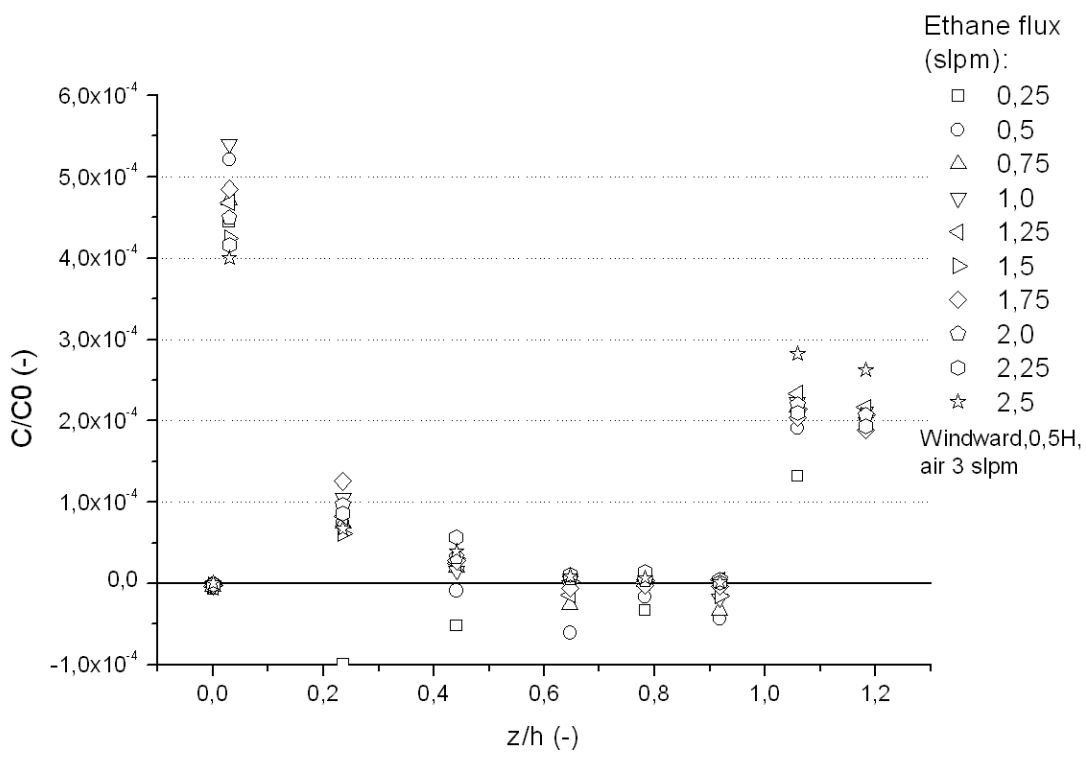

Figure 5: Windward façade concentration, distance $0,5 \mathrm{H}$, air emission. 


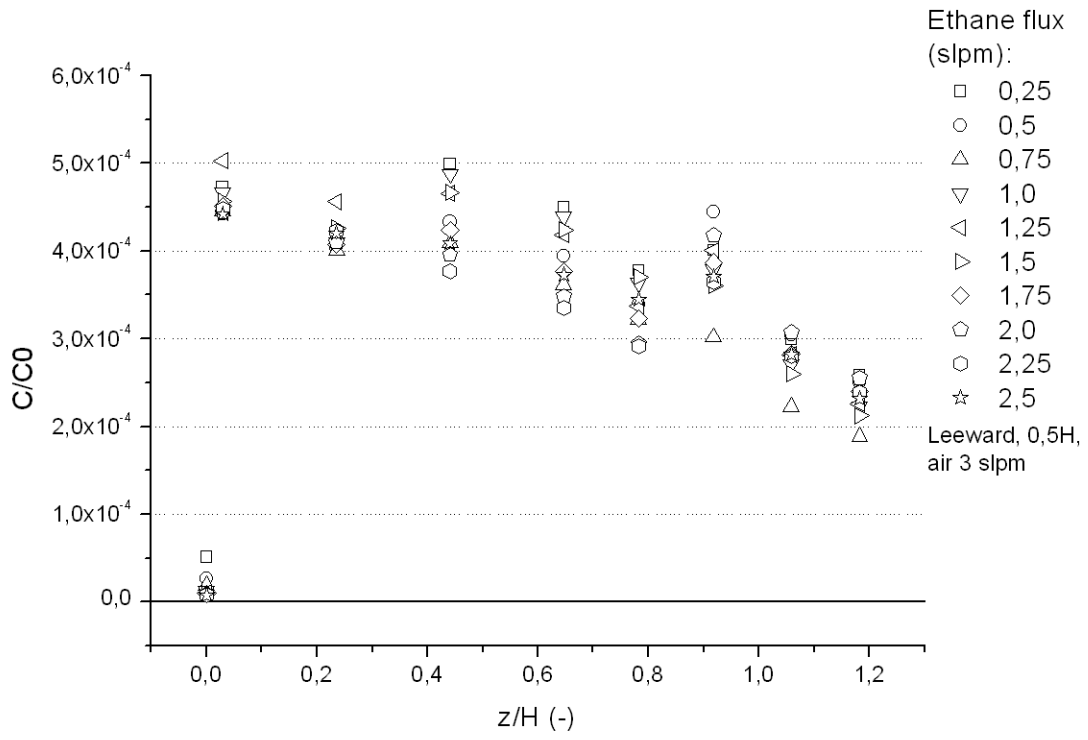

Figure 6: Leeward façade concentration, distance $0,5 \mathrm{H}$, air emission.

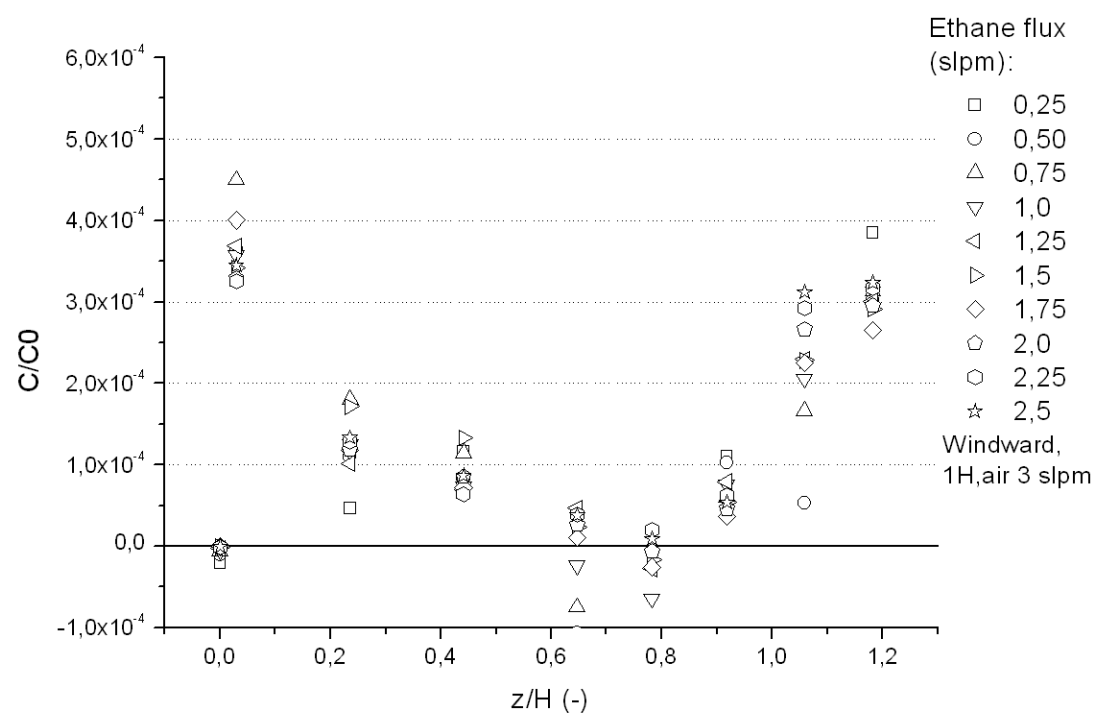

Figure 7: Windward façade concentration, distance $1 \mathrm{H}$, air emission. 


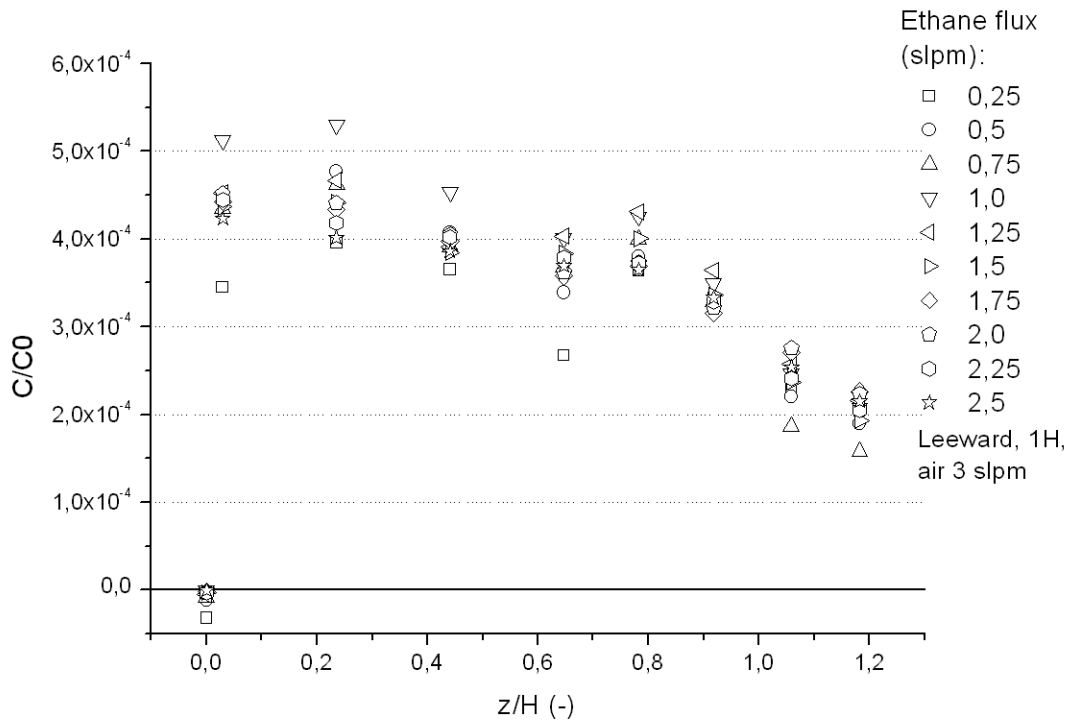

Figure 8: $\quad$ Leeward façade concentration, distance $1 \mathrm{H}$, air emission.

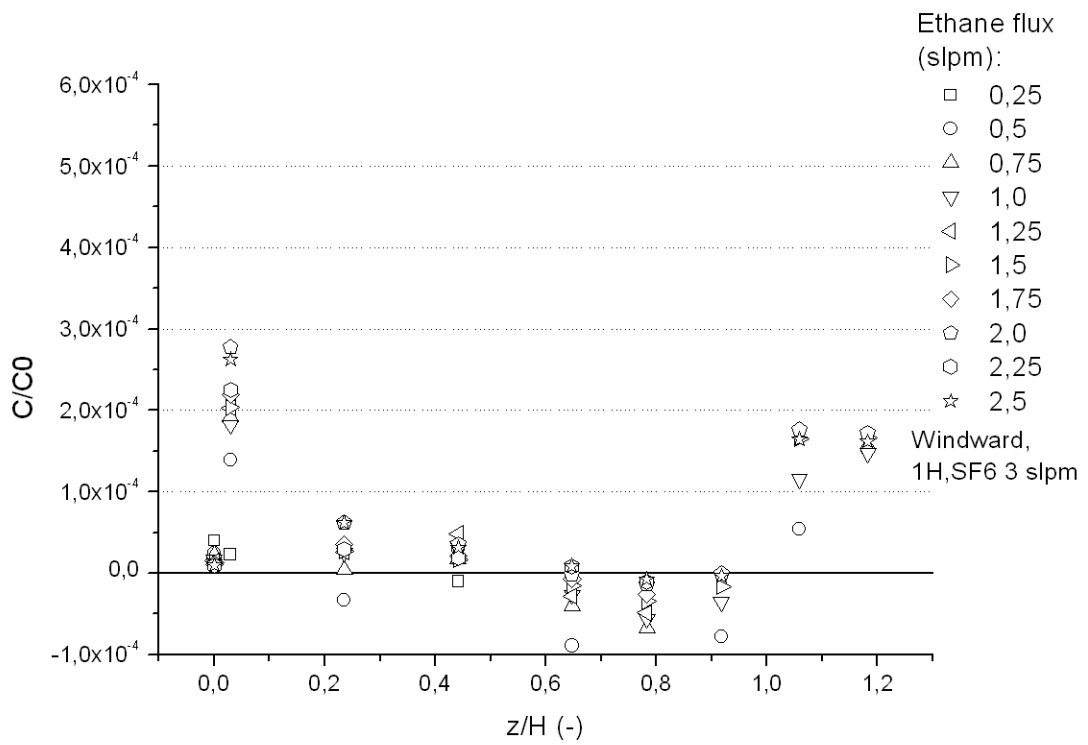

Figure 9: Windward façade concentration, distance 1H, SF6 emission. 


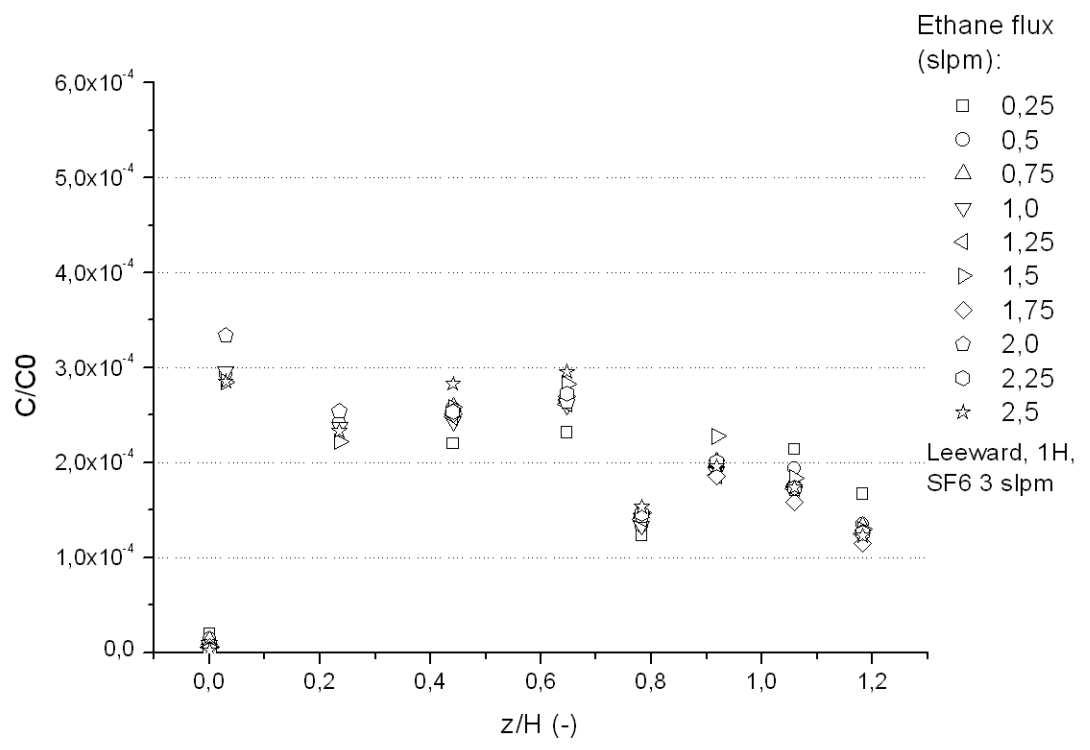

Figure 10: Leeward façade concentration, distance 1H, SF6 emission.

Distance of building from the source did not affect much the results on leeward side; on windward side the values were slightly higher for $0,5 \mathrm{H}$. This

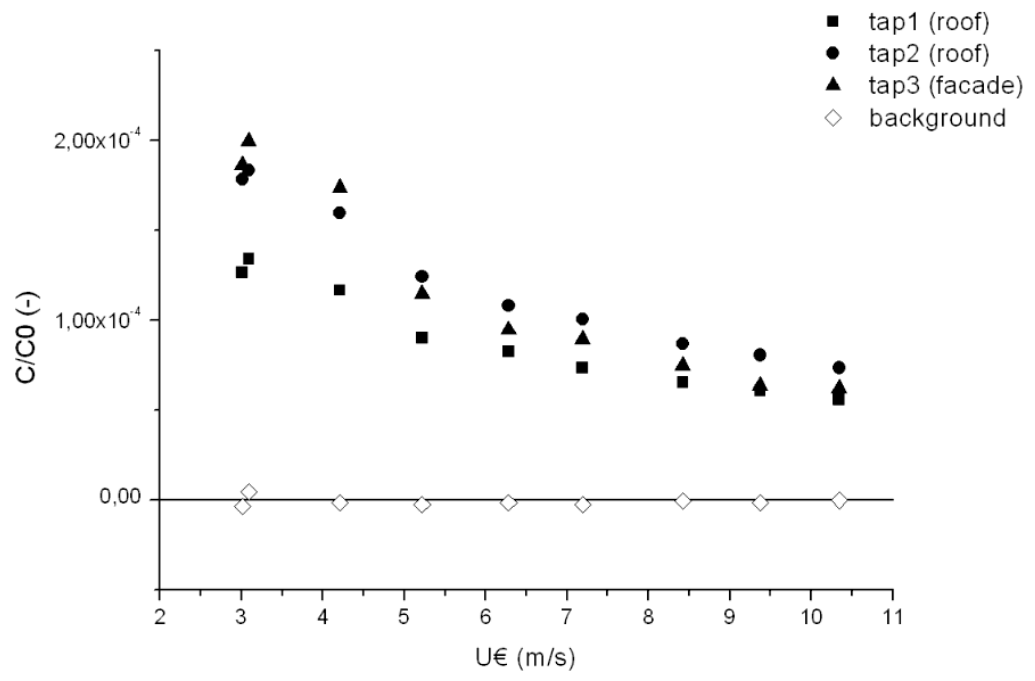

Figure 11: Influence of velocity in the wind tunnel. 
indicated that the emission was dispersed widely at distance $0,5 \mathrm{H}$ in front of the building probably due to the downwash effect.

Dense gas emission with SF6 affected the values mainly on windward side (see figures 7 and 9), where dense gas emission caused approx. half the values of neutral emission with air. The same effect happened on leeward side of the model (see figures 8 and 10).

Figure 11 presents decreasing concentration measured on the roof and on one tap in façade located on leeward side with increasing wind tunnel velocity.

\section{Conclusion}

Concentration measurements on simple rectangular building were performed in boundary layer wind tunnel. Significant differences between windward and leeward orientation of the façade have shown that concentration in the wake of the building are obviously higher than for windward orientation. Furthermore, dense gas emission caused lower relative concentration values on both sides. This effect requires more experiments to be done in order to clear its cause.

Future work will continue with these experiments and study neutral and dense gas dispersion near single building and groups of buildings and various types of terrain configuration, e.g. simple terrain slope or terrain wave. This work will serve for computer code verification as it was mentioned in the introduction.

\section{Acknowledgement}

This work was supported by research programme "SCENT", granted to VZLU by the Ministry of the Interior of the Czech Republic.

\section{References}

[1] Jirsak M., Ulman R., Chimney plumes simulation in the boundary layer wind tunnel. Advances in Air Pollution Series XI, WIT Press, 2003

[2] Ulman R., Physical modeling of heavy gas dispersion inside urban area. VZLU report Nr. R-4837, Prague, 2010

[3] Ulman R., Janour Z., Sedenkova H., Drbohlav J., The physical modeling of gas dispersion in topographically complicated terrain. Proceedings of EACWE4, eds. J. Náprstek and C. Fischer, Paper No.189, Prague, 2005

[4] Jirsak M., Zachoval D., Kabrhel M., Bittner M., Šmíd M., Tlaková a koncentrační měření na modelu 3D budovy k optimalizaci umístění vstupů a výstupů (in Czech). VZLU report Nr. R-4029, Prague, 2006

[5] Michalek P., Zacho D., Měření nízkých infiltračních průtoků na 3D modelu budovy (in Czech). VZLU report Nr. R-4846, Prague, 2010

[6] Michalek P., Zacho D., Effect of surface roughness on neutral and dense gas dispersion in the BLWT. Air Pollution $X X$, Ecology and the Environment volume 157, Paper DOI: 10.2495/AIR120111 
[7] Meroney R.N., Leitl B.M., Rafailidis S., Schatzmann M., Wind-tunnel and numerical modeling of flow and dispersion about several building shapes. Journal of Wind Eng. and Ind. Aerodyn. 81 (1999) 333-345

[8] Chavez M., Hajra B., Stathopoulos T., Bahloul A., Near-field pollutant dispersion in the built environment by CFD and wind tunnel simulations. Journal of Wind Eng. and Ind. Aerodyn. 99 (2011) 330-339

[9] Robins A., Castro I., Hayden P., Steggel N., Contini D., Heist D., A wind tunnel study of dense gas dispersion in a neutral boundary layer over a rough surface. Atmospheric Environment 35 (2001) 2243-2252

[10] Janour Z., Jurcakova K., Brych K., Dittrt F., Dittrich F., Potential risks at an industrial site: A wind tunnel study. Process Safety and Environmental Protection 88 (2010) 185-190

[11] Roberts P.T., Fryer-Taylor R.E.J., Wind-tunnel studies of roughness effects in gas dispersion. Atmospheric Environment Vol.28, No.11, pp. 1861-1870, 1994

[12] Snyder W.H., Guideline for fluid modeling of atmospheric diffusion, Environmental Protection Agency, Research Triangle Park, NC 27711, Report No.600/8-81-009 (1981)

[13] Wind tunnel studies of buildings and structures, ASCE manuals and reports on engineering practice No.67, N. Isyumov (ed.), Virginia, 1999

[14] Eurocode 1: Action on structures - Part 1-4: General actions - Wind loads (EN 1991-1-4) 